\title{
Control of eIF4E cellular localization by elF4E-binding proteins, 4E-BPs
}

\author{
LIWEI RONG, ${ }^{1,4}$ MARK LIVINGSTONE, ${ }^{1,4}$ RAMI SUKARIEH, ${ }^{1}$ EMMANUEL PETROULAKIS, ${ }^{1}$ \\ ANNE-CLAUDE GINGRAS, ${ }^{2}$ KATHERINE CROSBY, ${ }^{3}$ BRADLEY SMITH ${ }^{3}{ }^{2}$ ROBERTO D. POLAKIEWICZ, ${ }^{3}$ \\ JERRY PELLETIER, ${ }^{1}$ MARIA A. FERRAIUOLO, ${ }^{1}$ and NAHUM SONENBERG ${ }^{1}$ \\ ${ }^{1}$ Department of Biochemistry, McGill University, Montréal, Québec H3G 1Y6, Canada \\ ${ }^{2}$ Samuel Lunenfeld Research Institute, Mount Sinai Hospital, Toronto, Ontario M5G 1X5, Canada \\ ${ }^{3}$ Cell Signaling Technology, Inc., Danvers, Massachusetts 01923, USA
}

\begin{abstract}
Eukaryotic initiation factor (eIF) 4E, the mRNA 5 '-cap-binding protein, mediates the association of elF4F with the mRNA 5 ' -cap structure to stimulate cap-dependent translation initiation in the cytoplasm. The assembly of elF4E into the eIF4F complex is negatively regulated through a family of repressor proteins, called the elF4E-binding proteins (4E-BPs). elF4E is also present in the nucleus, where it is thought to stimulate nuclear-cytoplasmic transport of certain mRNAs. elF4E is transported to the nucleus via its interaction with $4 \mathrm{E}-\mathrm{T}$ (4E-transporter), but it is unclear how it is retained in the nucleus. Here we show that a sizable fraction $(\sim 30 \%)$ of $4 \mathrm{E}-\mathrm{BP} 1$ is localized to the nucleus, where it binds elF4E. In mouse embryo fibroblasts (MEFs) subjected to serum starvation and/or rapamycin treatment, nuclear 4E-BPs sequester elF4E in the nucleus. A dramatic loss of nuclear 4E-BP1 occurs in C-Ha-Ras-expressing MEFs, which fail to show starvation-induced nuclear accumulation of elF4E. Therefore, 4E-BP1 is a regulator of elF4E cellular localization.
\end{abstract}

Keywords: extracellular stimuli; intracellular localization; mRNA translation control; mTor signaling

\section{INTRODUCTION}

Cap-dependent translation initiation entails the recruitment of the $40 \mathrm{~S}$ small ribosomal subunits (and associated factors) to the $5^{\prime}$ end of the mRNAs (Hershey and Merrick 2000; Pestova et al. 2007). In this process, the mRNA 5' -cap structure, $\mathrm{m}^{7} \mathrm{GpppN}$ (where $\mathrm{N}$ is any nucleotide), is recognized by eukaryotic initiation factor (eIF) $4 \mathrm{E}$-one of the subunits of the eIF4F complex. The eIF4F complex also contains eIF4A, an ATP-dependent RNA helicase, which is thought to unwind secondary structure present

\footnotetext{
${ }^{4}$ These authors contributed equally to this work.

Abbreviations: 4E-BPs, eIF4E binding proteins; eIF, eukaryotic [translation] initiation factor; c-Ha-Ras, cellular Harvey rat sarcoma viral oncogene; DKO, [4E-BP1/4E-BP2] double knock-out; HA, hemagglutinin epitope; MEF, mouse embryonic fibroblast; mTOR, mammalian target of rapamycin.

Reprint requests to: Maria A. Ferraiuolo, Department of Biochemistry, McGill University, 3655 Promenade Sir William Osler, Montréal, Québec H3G 1Y6, Canada; e-mail: maria.ferraiuolo@elf.mcgill.ca; fax: (514) 398-1287; or Nahum Sonenberg, Department of Biochemistry, McGill University, 3655 Promenade Sir William Osler, Montréal, Québec H3G 1Y6, Canada; e-mail: nahum.sonenberg@mcgill.ca; fax: (514) 398-1287.

Article published online ahead of print. Article and publication date are at http://www.rnajournal.org/cgi/doi/10.1261/rna.950608.
}

at the $5^{\prime}$ end of the mRNA, and eIF4G (Rozen et al. 1990), a large scaffolding protein that binds to eIF4E, eIF4A, PABP, and eIF3, and consequently bridges the ribosome and the mRNA (Gingras et al. 1999b). eIF4E is the limiting factor in translation initiation under most circumstances and is an important effector of cellular proliferation, survival, and malignant transformation (Gingras et al. 1999a; Mamane et al. 2004; Graff et al. 2007).

The activity of eIF4E is regulated by a family of translational suppressors called the 4E-binding proteins (4E-BPs), which in mammals consists of three members: 4E-BP1, $4 \mathrm{E}-\mathrm{BP} 2$, and 4E-BP3. 4E-BP1 and 4E-BP2 are expressed in most tissues, whereas $4 \mathrm{E}-\mathrm{BP} 3$ exhibits a more restricted expression pattern (Poulin et al. 1998; Tsukiyama-Kohara et al. 2001). Binding of the 4E-BPs to eIF4E is controlled by the phosphorylation status of 4E-BPs (Pause et al. 1994; Gingras et al. 1998). The hypophosphorylated forms of $4 \mathrm{E}-\mathrm{BP}$ bind to eIF4E and prevent interaction of eIF4E with eIF4G, thus impairing cap-dependent translation (Haghighat et al. 1995). Conversely, in nutrient- or serumstimulated cells, 4E-BPs become hyperphosphorylated, releasing eIF4E for interaction with eIF4G and assembly into the eIF4F complex, resulting in enhanced translation. 
The best-characterized $4 \mathrm{E}-\mathrm{BP}$ is $4 \mathrm{E}-\mathrm{BP} 1$, which contains six known proline-directed Ser/Thr phosphorylation sites, among which at least two sites are phosphorylated directly by mTOR (mammalian target of rapamycin) (MotheSatney et al. 2000; Gingras et al. 2001; Wang et al. 2003). mTOR is a phylogenetically conserved Ser/Thr kinase that regulates cell growth and metabolism in response to diverse extracellular and intracellular cues. Growth factors and hormones (insulin/IGF), nutrients (amino acids/glucose), and high ATP/AMP ratio activate mTOR, resulting in hyperphosphorylation of 4E-BP1 (Fingar and Blenis 2004; Tokunaga et al. 2004; Wullschleger et al. 2006). Rapamycin, an inhibitor of mTOR, impairs the phosphorylation of $4 \mathrm{E}$ BP1 (Lin et al. 1995; Beretta et al. 1996).

While eIF4E is predominantly cytoplasmic, in mammalian cells and in yeast, a significant fraction (12\%-33\% in mammalian) is localized to the nucleus at steady-state levels as determined by biochemical fractionation studies and immunofluorescence analysis using several antibodies (Lejbkowicz et al. 1992; Lang et al. 1994; Dostie et al. 2000a). In the nucleus, eIF4E colocalizes with splicing factors in speckles (Lejbkowicz et al. 1992; Dostie et al. $2000 \mathrm{a}, \mathrm{b})$. The nuclear import of eIF4E is mediated by $4 \mathrm{E}-\mathrm{T}$ (eIF4E-transporter), which binds to eIF4E through a conserved binding motif shared with 4E-BPs and eIF4G, and simultaneously interacts with nuclear import receptors, importin $\alpha / \beta$ (Dostie et al. 2000a). While the role of eIF4E in the nucleus has not been as extensively studied as its cytoplasmic role, it is known to promote the nuclear export of a subset of mRNAs (Rousseau et al. 1996; Topisirovic et al. 2003). How the steady-state pool of nuclear eIF4E is maintained and regulated is not clear.

Biochemical fractionation experiments have previously led to the conclusion that 4E-BP1 localization is restricted to the cytoplasm (Kim and Chen 2000; Kleijn et al. 2002; Zhang et al. 2002). However, in these studies the possibility that $4 \mathrm{E}-\mathrm{BP} 1$ leaked from the nucleus during the fractionation procedures due to its small molecular mass was not addressed. Studies were done on the localization of $4 \mathrm{E}-\mathrm{BP}$ by immunofluorescence and immunohistocytochemistry, but they did not include the use of 4E-BP knock-out or knocked-down cells (Castellvi et al. 2006). Therefore, the question of whether 4E-BP1 localizes to the nucleus under physiological conditions still remains unresolved. Here, using a monoclonal antibody to 4E-BP1, we show that a sizeable fraction $(\sim 30 \%)$ of endogenous $4 \mathrm{E}-\mathrm{BP} 1$ is localized to the nucleus by immunofluorescence. Importantly, we demonstrate that $4 \mathrm{E}-\mathrm{BP} 1$ regulates the subcellular localization of eIF4E under stress conditions. The $4 \mathrm{E}-$ $\mathrm{BP} 1-$ dependent regulation of eIF4E localization becomes conspicuous upon serum starvation or rapamycin treatment and correlates well with the dephosphorylation of $4 \mathrm{E}$ $\mathrm{BP} 1$ and its increased binding to eIF4E. We also show that $4 \mathrm{E}-\mathrm{BP} 1$, and consequently eIF4E, can no longer localize to the nucleus in MEFs that express the c-Ha-Ras protein.

\section{RESULTS}

\section{E-BP1 is present in the nuclei of cultured cells and adult mouse tissues}

To study the localization of $4 \mathrm{E}-\mathrm{BP} 1$ in cells, a rabbit monoclonal 4E-BP1 antibody (Cell Signaling Technology; clone 53H11) was used in immunofluorescence studies. We first assessed the specificity of this antibody by Western blot analysis of total protein lysates from wild-type, $4 \mathrm{E}-\mathrm{BP} 1^{-/-}$, $4 \mathrm{E}-\mathrm{BP} 2^{-1-}$, and DKO (4E-BP1 $\left.1^{-1-} / 4 \mathrm{E}-\mathrm{BP} 2^{-/-}\right) \mathrm{MEFs}$. The antibody recognized specifically $4 \mathrm{E}-\mathrm{BP} 1$, as it did not interact with proteins from $4 \mathrm{E}-\mathrm{BP} 1^{-/-} \mathrm{MEFs}$ (Fig. 1A, cf. lanes 1 and 2). A comparison of extracts from wild-type and $4 \mathrm{E}-\mathrm{BP} 2^{-/-}$MEFs demonstrates that this anti-4E-BP1 antibody does not cross-react even with the closest related protein, 4E-BP2 (Fig. 1A, cf. lanes 1,3 and lane 2). Both wild-type and DKO MEFs were stained with this antibody and subjected to analysis by flow cytometry to measure relative fluorescence intensity (Fig. 1B). When the primary antibody was omitted, both wild-type and DKO MEFs exhibited very similar low levels of fluorescence intensity; however, when the 4E-BP1 antibody was included, wildtype and DKO MEFs exhibit more than a 10-fold difference in mean fluorescence intensity, representing a 4E-BP1dependent retention of the Alexa 488-conjugated secondary antibody in MEFs (Fig. 1B). These data clearly demonstrate that the anti-4E-BP1 rabbit monoclonal antibody specifically recognizes $4 \mathrm{E}-\mathrm{BP} 1$ under conditions used in the subsequent immunostaining experiments. Indeed, when immunostained cells were scanned by confocal microscopy, a very strong signal was detected in wild-type but not DKO cells (Fig. 1C). Strikingly, a prominent nuclear staining of 4E-BP1 was observed. The nuclear localization of 4E-BP1 is not restricted to MEFs, as immunostaining with this antibody yielded a nuclear signal in a variety of cell types, including NIH/3T3, Rat1A, COS-7, and HeLa S3 (data not shown).

To determine the relative concentration of $4 \mathrm{E}-\mathrm{BP} 1$ in the nucleus versus the cytoplasm, the signal intensity was quantified in MEFs using confocal microscopy. Twenty immunostained cells were randomly chosen for scanning, and no significant difference from cell to cell was observed. Each cell was scanned using a $\mathrm{Z}$ section with a disk thickness of $0.65 \mu \mathrm{m}$. This manipulation produced 1216 continuous image slices from the dorsal to the basal facade of every scanned cell. Using ImageJ (National Institutes of Health), the pixel intensity from each slice was measured and summed to represent the immunofluorescence of a cell. The intensity of 4E-BP1 nuclear fluorescence is $\sim 5.5$-fold greater than that in the cytoplasm. Because the volume of the cytoplasm is $\sim 10$ times larger than that of the nucleus in MEFs, the amount of $4 \mathrm{E}$ $\mathrm{BP} 1$ in the nucleus is estimated to be $\sim 30 \%$ of the total protein. 
A

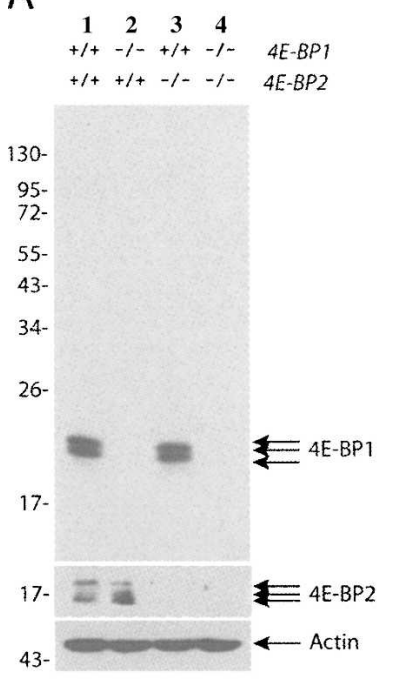

B
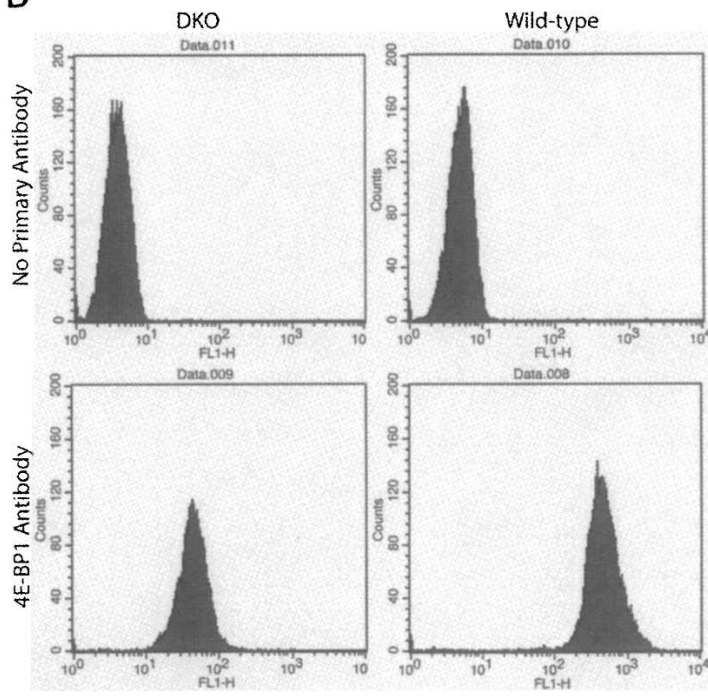

C

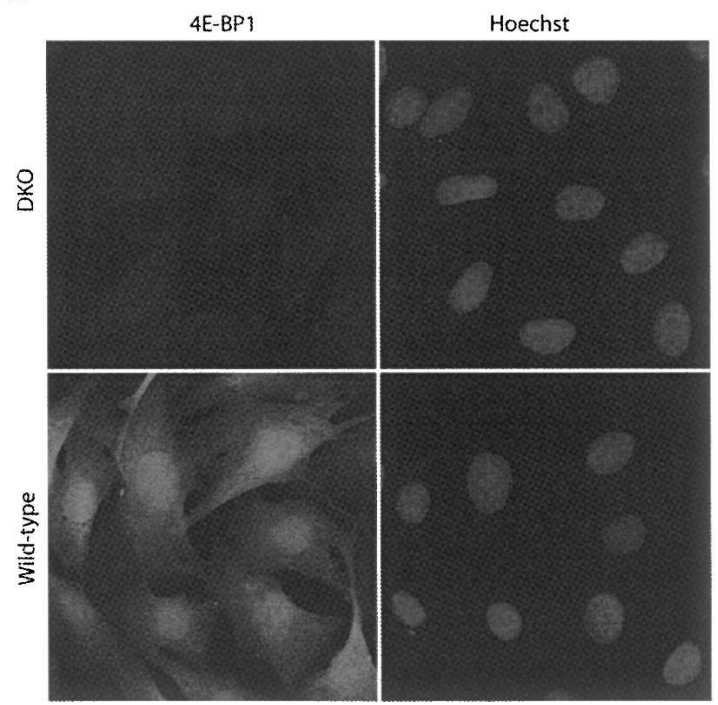

FIGURE 1. Characterization of anti-4E-BP1 rabbit monoclonal antibody (clone 53H11). (A) Western blot analysis of lysates from wild-type, $4 \mathrm{E}-\mathrm{BP} 1^{-1-}, 4 \mathrm{E}-\mathrm{BP} 2^{-l-}$, and DKO $\left(4 \mathrm{E}-\mathrm{BP}^{-l-}\right.$, $4 \mathrm{E}-\mathrm{BP} 2^{-1-}$ ) MEFs, using anti-4E-BP1 and anti-4E-BP2 antibodies. (B) Flow cytometric analysis of wild-type and DKO MEFs subjected to immunostaining with anti-4E-BP1 antibody. (C) Immunofluorescent detection of 4E-BP1 in wild-type and DKO MEFs. 4E-BP1 was stained by anti-4E-BP1 and AlexaFluor488 conjugated secondary antibody.

To rule out the possibility that the presence of $4 \mathrm{E}-\mathrm{BP} 1$ in the nucleus is caused by fixation or other manipulations of the cells, living cells transiently expressing 4E-BP1-CFP fusion protein were subjected to photobleaching assays (Fig. 2A, a representative experiment). Quantification of the average nuclear fluorescent intensity following photobleaching is shown in Figure 2B. After bleaching of the nucleus for $5 \mathrm{sec}$, total recovery of the nuclear fluorescence was observed within $300 \mathrm{sec}$ (Fig. 2B). These results demonstrate that $4 \mathrm{E}-\mathrm{BP} 1$ localizes to the nucleus in vivo and that the nuclear import of $4 \mathrm{E}-\mathrm{BP} 1$ is a rapid process.
To verify that the observed nuclear localization of 4E-BP1 occurs in tissues, immunohistochemical analysis of multiple murine tissues was performed. $4 \mathrm{E}-$ $\mathrm{BP}^{-1-}$ mouse tissues were used as a negative control. 4E-BP1 staining was observed in kidney (Fig. 3), adipose tissue, colon, liver, heart, lung, muscle, ovary, pancreas, and spleen (data not shown). Higher magnification images reveal that $4 \mathrm{E}-\mathrm{BP} 1$ is present in the nuclei and cytoplasm of adult mouse kidney (Fig. 3B).

\section{Localization of 4E-BP1 to the nucleus is independent of phosphorylation or ability to bind eIF4E}

Phosphorylation of 4E-BP1 occurs on several sites (Thr37/46, Ser65, Thr70) in response to various intrinsic and environmental cues (Gingras et al. 1999a). To examine whether phosphorylation of 4E-BP1 affects its localization, we employed various conditions to alter the phosphorylation status of the protein. The conditions that induced $4 \mathrm{E}-$ BP1 dephosphorylation included serum starvation or rapamycin treatment for $24 \mathrm{~h}$, or serum starvation for $24 \mathrm{~h}$ followed by rapamycin treatment for $1 \mathrm{~h}$. None of these conditions resulted in a noticeable redistribution of $4 \mathrm{E}-\mathrm{BP} 1$ in MEFs (Fig. 4A), NIH/3T3, Rat1A, COS7, or HeLa S3 cells (data not shown). Serum-deprivation and rapamycin treatment each decreased the phosphorylation of $4 \mathrm{E}-\mathrm{BP} 1$, while the combination of serum starvation followed by rapamycin treatment most dramatically reduced 4E-BP1 phosphorylation (Fig. $4 \mathrm{~B})$. Consistent with these data, inhibition of 4E-BP1 phosphorylation by PI3K inhibitors such as Wortmannin and LY294002 (Sigma) or by knockdown of mTOR using a commercially available siRNA (Cell Signaling Technology, no. 6381) failed to alter 4E-BP1 subcellular localization (data not shown).

To study whether the association of $4 \mathrm{E}-\mathrm{BP} 1$ with eIF4E affects 4E-BP1 localization, DKO MEFs were infected with retroviruses expressing $\mathrm{HA}-4 \mathrm{E}-\mathrm{BP} 1$ or the mutant proteins, 4E-BP1(4Ala) or 4E-BP1( $\triangle 4 \mathrm{EBS})$. 4E-BP1(4Ala) constitutively binds to eIF4E (data not shown) because four of its Ser/Thr-Pro phosphorylation sites have been mutated to 
A
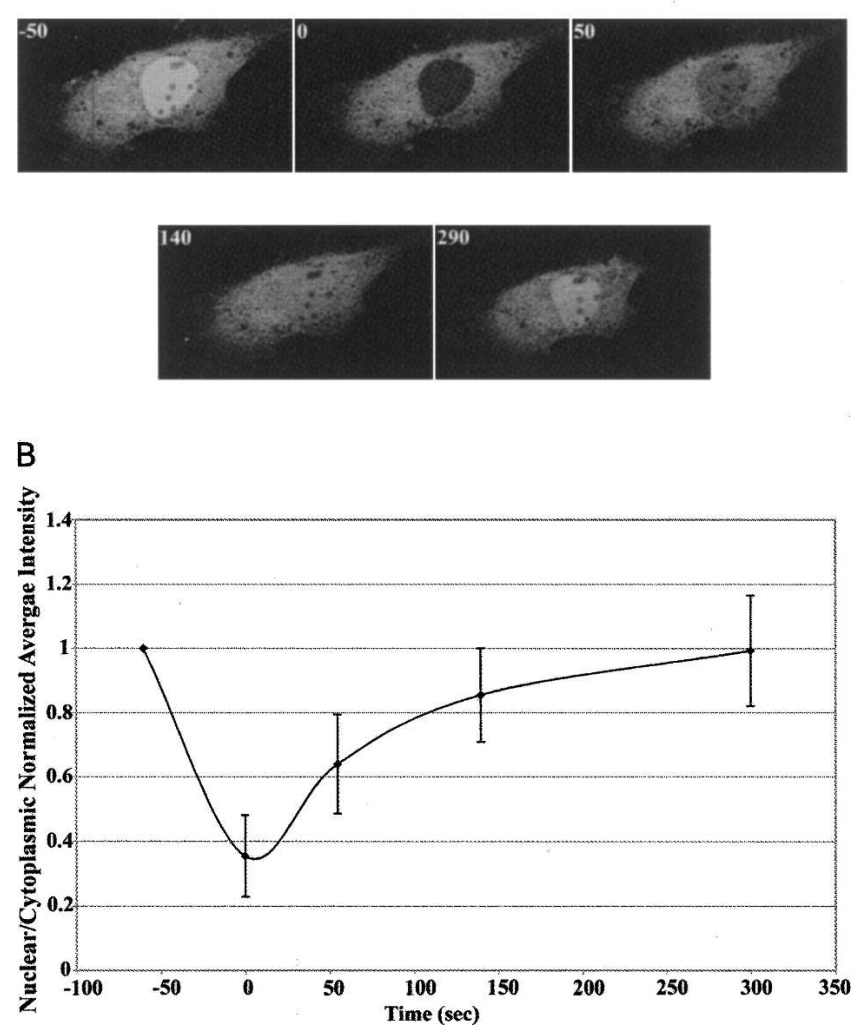

FIGURE 2. Nuclear localization of $4 \mathrm{E}-\mathrm{BP} 1$ in living cells. MEFs transiently transfected with pcDNA3-4E-BP1-CFP were subjected to selective photobleaching of the nucleus and fluorescence recovery was monitored. (A) The nuclear area was photobleached for $5 \mathrm{sec}$, recovery of fluorescence was monitored continuously, and pictures were taken at the indicated time intervals over a 300 - to 600 -sec period. (B) The average ratio of nuclear to cytoplasmic pixel intensity during the process of recovering from photobleaching. The results are the average of readings taken from seven different cells. Error bars represent standard deviation.

alanines. $4 \mathrm{E}-\mathrm{BP} 1(\Delta 4 \mathrm{EBS})$ is a mutant in which the eIF4E binding site was deleted and, consequently, can no longer bind to eIF4E (Gingras et al. 1999a). Stable cell lines expressing wild-type $4 \mathrm{E}-\mathrm{BP} 1$ or mutants, in which exogenous $4 \mathrm{E}-\mathrm{BP}$ was expressed at levels that were comparable to endogenous levels, were established. Staining of the stably expressing cell lines with an anti-HA antibody shows a similar distribution pattern to that of endogenous protein (Fig. 5). Therefore, the presence of 4E-BP1 in the nucleus is neither affected by constitutive binding to eIF4E nor by a deficiency in binding to eIF4E. Because a 4E-BP2 antibody suitable for immunostaining experiments was not identified, HA-4E-BP2 expression was monitored using an anti-HA antibody for immunofluorescence in DKO MEFs. HA-tagged 4E-BP2 exhibited similar localization to that of HA-4E-BP1 in these cells, and the nuclear-to-cytoplasmic ratio of HA-4E-BP2 did not change following serum starvation and rapamycin treatment (Fig. 5).

\section{eIF4E is excluded from the nucleus in 4E-BP1/4E-BP2 DKO MEFs}

Because $4 \mathrm{E}-\mathrm{BPs}$ bind to eIF4E, it was pertinent to study eIF4E localization in MEFs lacking 4E-BPs. We used a monoclonal antibody (BD Transduction Labs) that recognizes almost exclusively cytoplasmic eIF4E under physiological conditions (see manufacturer's technical data sheet; catalog no. 610270). In serum-deprived or rapamycintreated cells, the fraction of eIF4E in the nucleus significantly increased from $\sim 1 \%$ to $\sim 20 \%$, while serum starvation in conjunction with rapamycin had the most dramatic effect on eIF4E nuclear accumulation $(\sim 30 \%$ in the nucleus) (Fig. 6). In sharp contrast, eIF4E failed to accumulate in the nucleus of DKO cells in response to serum starvation and rapamycin treatments (Fig. 6A), demonstrating that $4 \mathrm{E}-\mathrm{BPs}$ are required for eIF4E nuclear accumulation. A similar redistribution of eIF4E was observed in other cells, including HeLa S3, NIH/3T3, and

A

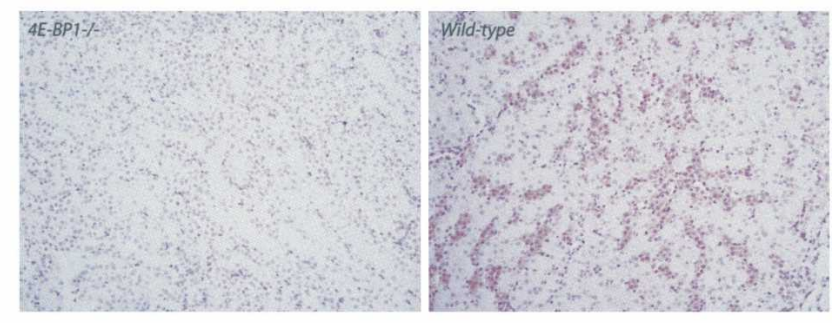

B

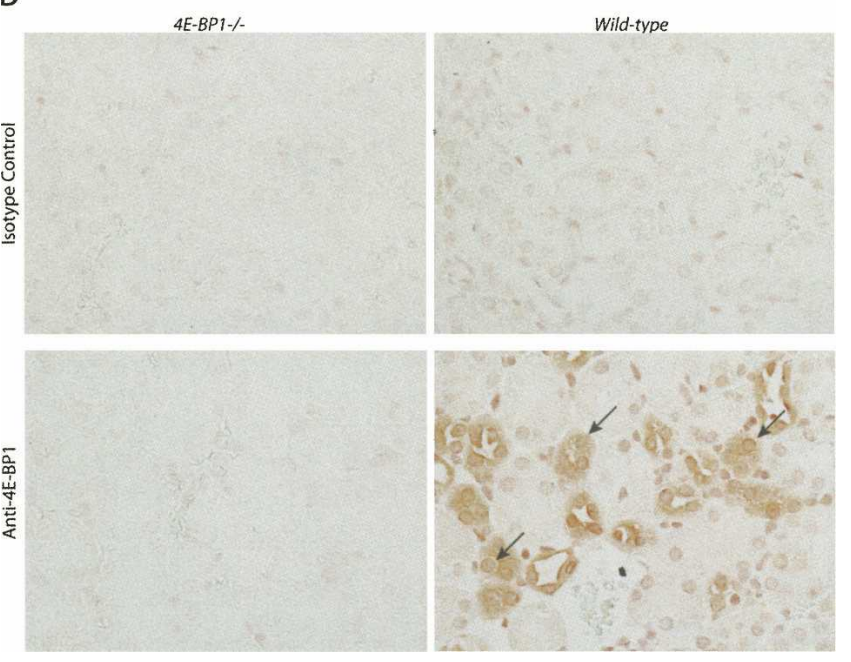

FIGURE 3. Immunohistochemical analysis of 4E-BP1 localization in adult mouse kidney demonstrates the presence of nuclear 4E-BP1 in vivo. (A) Low magnification comparison of wild-type and 4E-BP1 $1^{-/-}$ mouse kidney sections subjected to immunohistochemical staining with 4E-BP1 monoclonal antibody and hematoxylin counter-stain of select cells within the medulla. (B) Higher magnification and omission of hematoxylin allows visualization of nuclear 4E-BP1 (indicated by the position of the arrowheads) in adult mouse kidney. 
A

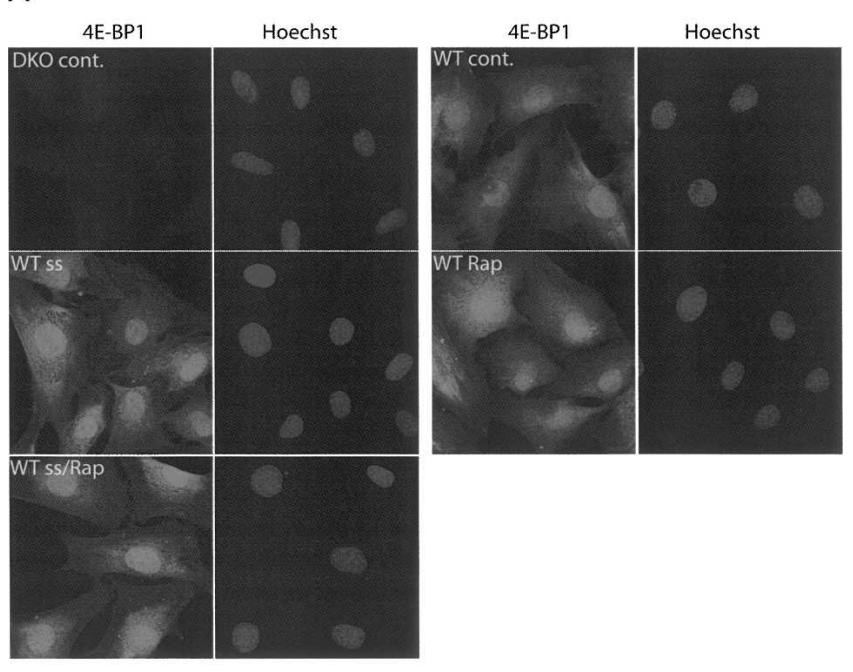

B

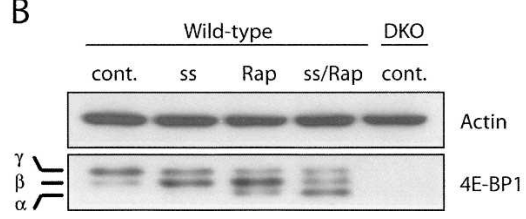

FIGURE 4. Localization of endogenous 4E-BP1 to the nucleus is unaffected by conditions that reduce its phosphorylation status. (A) Wild-type MEFs were subjected to immunocytochemical analysis under control (WT cont.) conditions, after 24-h serum starvation (ss), following rapamycin (Rap) treatment $(10 \mathrm{nM}, 24 \mathrm{~h})$, or after serum starvation/rapamycin dual treatment (ss/Rap). DKO MEFs were stained in parallel as a negative control. (B) Western blotting showing phosphorylation status of $4 \mathrm{E}-\mathrm{BP} 1$ in wild-type MEFs under the different conditions. The positions of hypophosphorylated $(\alpha)$, hyperphosphorylated $(\gamma)$, and intermediately phosphorylated $(\beta) 4 \mathrm{E}$ BP1 are indicated.

Rat 1A (data not shown), and with other eIF4E antibodies, including a rabbit polyclonal antibody 5853 (Lejbkowicz et al. 1992), and another monoclonal that recognizes cytoplasmic eIF4E (Kimball et al. 2003; Ferraiuolo et al. 2005; data not shown).

To determine whether the differential staining observed in wild-type versus DKO cells under serum starvation and rapamycin treatment is a consequence of the lack of $4 \mathrm{E}$ BPs, rather than other unintended effects of cell manipulations, we examined the localization of eIF4E in DKO cells that stably expressed HA-4E-BP1 or HA-4E-BP2. Exogenous expression of $4 \mathrm{E}-\mathrm{BP} 1$ or $4 \mathrm{E}-\mathrm{BP} 2$ restored the wildtype phenotype in DKO MEFs (Fig. 6B). This demonstrates that the defective regulation of eIF4E localization in DKO MEFs is due directly to the absence of $4 \mathrm{E}-\mathrm{BPs}$ and that both 4E-BP1 and 4E-BP2 control eIF4E localization. Consistent with this conclusion, eIF4E was present in the nucleus of single knockout $4 \mathrm{E}-\mathrm{BP} 1^{-/-}$or $4 \mathrm{E}-\mathrm{BP} 2^{-1-}$ MEFs in response to starvation and rapamycin treatment (data not shown).

\section{Constitutive binding of $4 \mathrm{E}-\mathrm{BP}$ to elF4E results in nuclear accumulation of elF4E}

Next, we wished to determine whether the interaction of $4 \mathrm{E}-\mathrm{BP} 1$ with eIF4E is necessary to retain eIF4E in the nucleus. To this end, we examined the cellular distribution of eIF4E in DKO MEFs expressing the 4E-BP1 mutant HA$4 \mathrm{E}-\mathrm{BP} 1$ (4Ala) or HA-4E-BP1( $\triangle 4 \mathrm{EBS})$. eIF4E was present in the nucleus of HA-4E-BP1(4Ala)-expressing cells, even under normal growth conditions, while it was cytoplasmic in cells expressing the 4E-BP1( $\triangle 4 \mathrm{EBS}$ ) (Fig. 6C). Strikingly, HA-4E-BP1( $\Delta 4 \mathrm{EBS})$ failed to confer eIF4E nuclear localization under starved/rapamycin conditions (Fig. 6C). These results clearly demonstrate that the interaction of 4E-BP with eIF4E is absolutely required for serum starvation-induced eIF4E relocalization to the nucleus.

\section{elF4E localization in the nucleus is dependent on nuclear 4E-BPs}

To further demonstrate that eIF4E localization to the nucleus is dependent on the presence of $4 \mathrm{E}-\mathrm{BP}$ in the

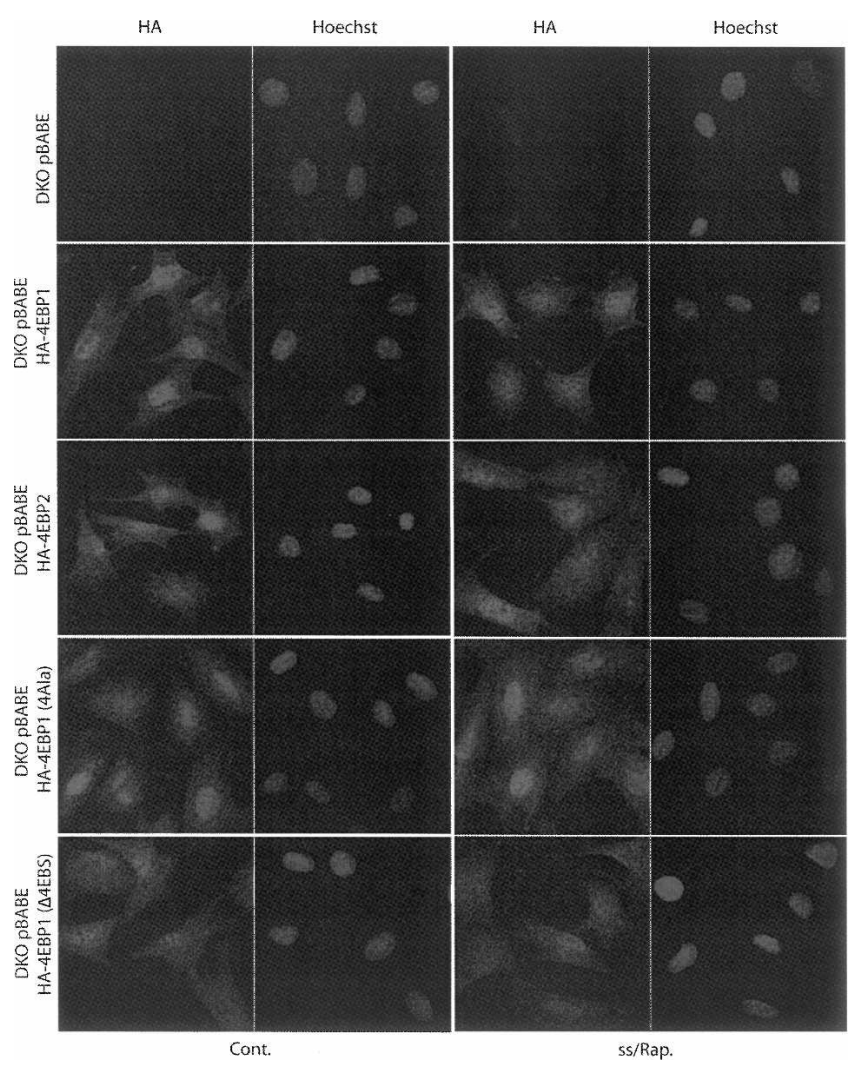

FIGURE 5. Localization of HA-4E-BPs is unaffected by mutations that alter eIF4E binding. DKO MEFs with stable expression of exogenous HA tagged wild-type 4E-BP1, 4E-BP1(4Ala), 4E$\mathrm{BP} 1(\Delta 4 \mathrm{EBS})$, or wild-type 4E-BP2 were subjected to immunocytochemical analysis using anti-HA mouse monoclonal antibody and AlexaFluor594 conjugated secondary antibody. The stable cell lines were established by infection of DKO MEFs with retroviruses expressing various $4 \mathrm{E}-\mathrm{BP}$ constructs. 
A
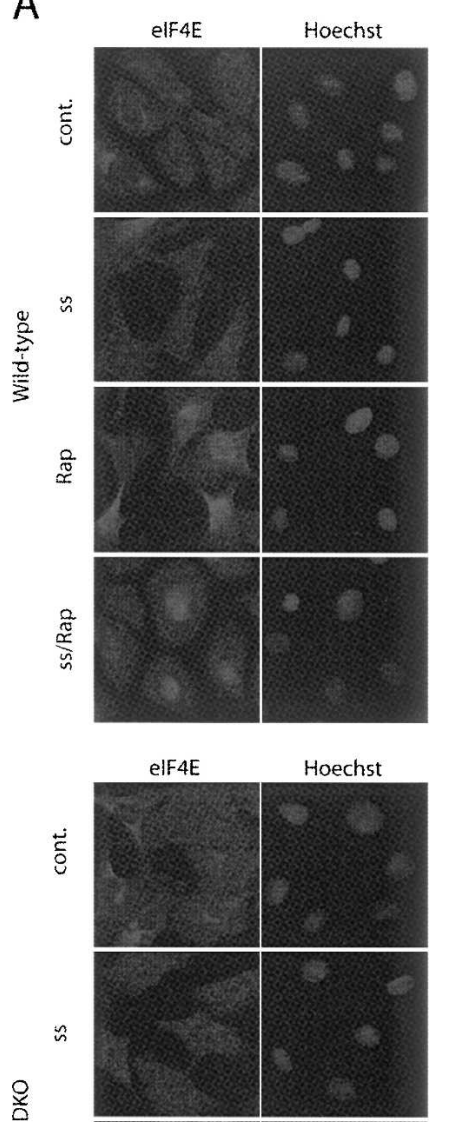

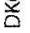

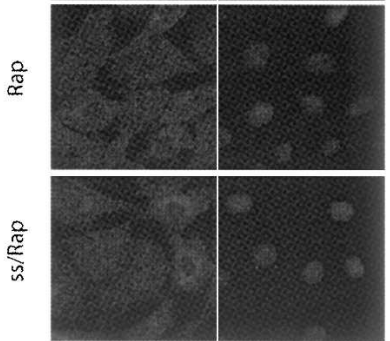

B

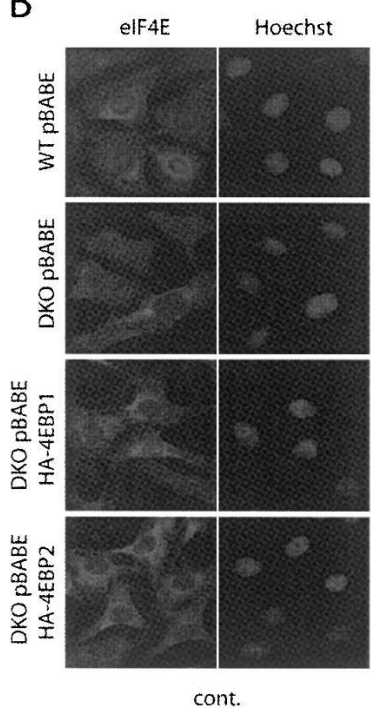

C

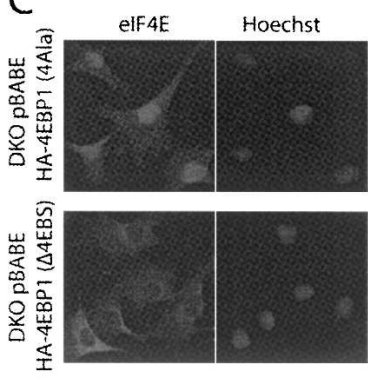

cont.
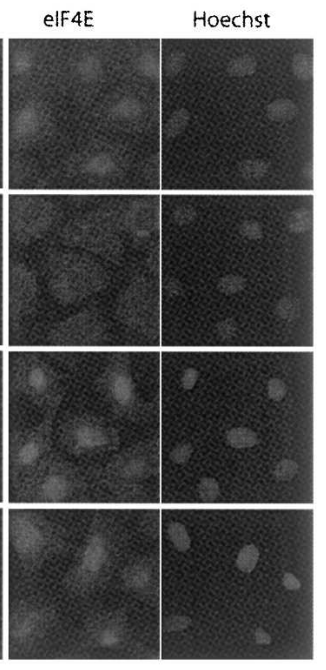

ss/Rap
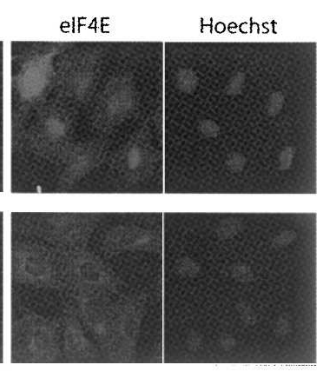

ss/Rap

FIGURE 6. Serum starvation and/or rapamycin induce nuclear accumulation of eIF4E. $(A)$ Wild-type and DKO MEFs were subjected to immunocytochemical analysis following serum starvation (ss), rapamycin treatment (Rap), and dual treatment (ss/Rap). (B) Localization of eIF4E in DKO cells that express HA-4E-BP1 or HA-4E-BP2. (C) Interaction of 4E-BP1 with eIF4E is necessary for the localization of eIF4E in the nucleus. 4E-BP1(4Ala) and $4 \mathrm{E}$ $\mathrm{BP} 1(\Delta 4 \mathrm{EBS})$ mutants were used. eIF4E was stained with a mouse monoclonal antibody and AlexaFluor594 conjugated secondary antibody. The cells lines that express exogenous 4E-BP proteins were established by infection of DKO MEFs with retroviral-based constructs.

nucleus, we searched for conditions that would exclude $4 \mathrm{E}$ $\mathrm{BP} 1$, and consequently eIF4E, from the nucleus. We found that 4E-BP1 was exclusively cytoplasmic in c-Ha-Rasexpressing MEFs (Fig. 7). This result demonstrates that the cellular localization of $4 \mathrm{E}-\mathrm{BP} 1$ is subject to regulation related to expression of Ras. Consistent with our previous findings, those cells exhibiting exclusively cytoplasmic 4E-BP1 failed to display the serum starvation and/ or rapamycin-induced nuclear accumulation of eIF4E phenotype (Fig. 7).

\section{DISCUSSION}

Herein we provide evidence that a sizable fraction $(\sim 30 \%)$ of $4 \mathrm{E}-\mathrm{BP} 1$ is present in the nucleus, contrary to earlier reports (Kim and Chen 2000; Kleijn et al. 2002). The use of biochemical fractionation techniques suggested that $4 \mathrm{E}-\mathrm{BPs}$ reside exclusively in the cytoplasm, but these techniques are subject to limitations due to leakage of small proteins from the nucleus. We provide compelling evidence for the nuclear localization of 4E-BP1 as follows: (1) a null cell line that does not express $4 \mathrm{E}-$ BP1 was not stained with a monoclonal antibody, providing strong evidence that the observed fluorescent signal is due to 4E-BP1 (Fig. 1); (2) in vivo localization of CFP-4E-BP, which precludes artifacts arising from fixing and/ or labeling cells for indirect immunofluorescence analysis, yielded similar results; (3) Western blot analysis with an antibody generated against 4E-BP1 detects bands specific to $4 \mathrm{E}-\mathrm{BP} 1$ that are not present in $4 \mathrm{E}-\mathrm{BP}^{-1-}$ cells; and (4) the nuclear localization of 4E-BP1 is confirmed in multiple cell lines and tissues. The mechanism by which $4 \mathrm{E}-\mathrm{BP}$ enters the nucleus, however, remains to be elucidated.

We provide evidence that $4 \mathrm{E}-\mathrm{BP}$ regulates the localization of its binding partner, eIF4E. We reported that $4 \mathrm{E}-\mathrm{T}$ mediates the nuclear import of eIF4E by the importin $\alpha / \beta$ pathway (Dostie et al. 2000a). In the nucleus, eIF4E colocalizes with splicing factors in speckles (Dostie et al. 2000b). We propose that 4E-BP controls the amount of nuclear eIF4E by regulating its release from the nucleus. The regulation of nuclear eIF4E by $4 \mathrm{E}$ $\mathrm{BP}$ is supported by data demonstrating that HA-4E-BP1(4Ala), which is constitutively bound to eIF4E, causes nuclear accumulation of eIF4E even under standard conditions (Fig. 6C). A 4E-BP1 mutant lacking the eIF4E binding site failed to cause the nuclear accumulation phenotype observed under stress conditions (Fig. 6C). Furthermore, a loss of nuclear 4E$\mathrm{BP}$ in Ras-expressing MEFs is accompanied by a loss of nuclear eIF4E under stress conditions. Therefore, eIF4E is retained and released from the nucleus in a $4 \mathrm{E}-\mathrm{BP}-$ dependent manner. The presence of $4 \mathrm{E}-\mathrm{BP}$ in the nucleus provides a means to regulate the release of eIF4E from the 


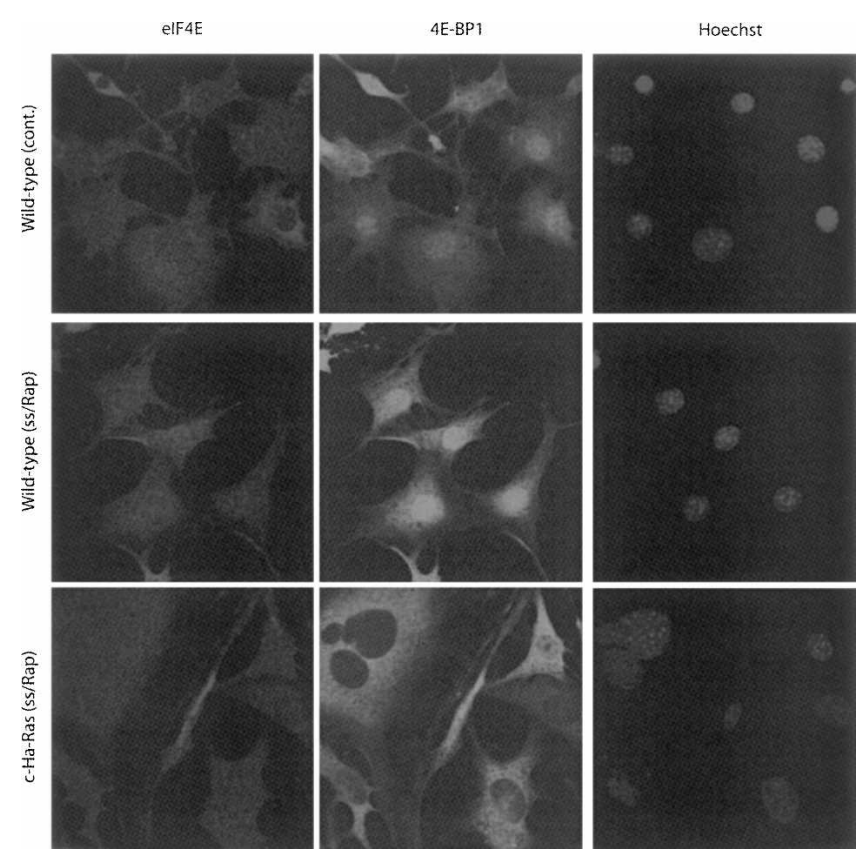

FIGURE 7. 4E-BP1 is cytoplasmic in c-Ha-Ras-expressing MEFs, precluding nuclear accumulation of eIF4E in response to serum starvation plus rapamycin (ss/Rap) dual treatment. Cells were subjected to immunofluorescence analysis using eIF4E mouse monoclonal (BD Transduction Labs) and 4E-BP1 (53H11) antibodies.

nucleus and may prevent the untimely export of eIF4Ebound mRNAs. What could be the advantage of sequestering eIF4E in the nucleus under stress conditions known to inhibit cap-dependent translation? One possibility is that sequestering eIF4E in the nucleus is more efficient than in the cytoplasm, because 4E-BPs do not need to compete with eIF4G and 4E-T, which are mainly cytoplasmic. Another possible advantage is that nuclear recruitment by $4 \mathrm{E}-\mathrm{BP}$ eliminates the necessity for incorporation of eIF4E into cellular structures, such as insoluble granules formed by eIF4G and heat shock proteins (Cuesta et al. 2000). Thus, retention of eIF4E in the nucleus under stress conditions could be an effective means to inhibit capdependent translation. In this regard, it is of interest that mTOR was reported to be a nucleocytoplasmic shuttling protein whose nuclear localization is required for $4 \mathrm{E}-\mathrm{BP} 1$ phosphorylation (Kim and Chen 2000; Zhang et al. 2002). Thus, activation of the mTOR pathway is expected to cause the phosphorylation of 4E-BP in the nucleus and the release of eIF4E to the cytoplasm to stimulate translation.

The mechanism by which 4E-BP enters and exits the nucleus is unclear; however, previous work has shown that small proteins $(<70 \mathrm{kDa})$ traverse the nuclear pore complex by simple diffusion (Hicks and Raikhel 1995; Wei et al. 2003). 4E-BP is present in the nucleus at steadystate and under stress conditions and is a small protein and does not possess the canonical nuclear localization signals or nuclear export signals (Gorlich and Kutay 1999).
However, given that c-Ha-Ras expression induces exclusively cytoplasmic 4E-BP1 localization, the nucleocytoplasmic trafficking of $4 \mathrm{E}-\mathrm{BP}$ appears to be a regulated process and provides a model system to investigate the regulation of $4 \mathrm{E}-\mathrm{BP}$ translocation. The mechanism by which c-Ha-Ras prevents nuclear 4E-BP1 localization is not immediately clear, although cytoplasmic retention of nuclear proteins has been reported in Ha-Ras overexpressing embryonic fibroblasts after focus formation (Knippschild et al. 1996). Overexpression of the c-Ha-Ras oncogene is known to induce mTOR phosphorylation through activation of the PI3K/AKT pathway (Marte and Downward 1997). Activated AKT in turn phosphorylates and suppresses TSC2, which results in mTOR activation (Inoki et al. 2002; Reiling and Sabatini 2006; Wullschleger et al. 2006). Erk1/2, another target of the Ras signal transduction route, can phosphorylate and inactivate TSC2 on Ser664 (Ma et al. 2005). It is of interest that increased phosphorylation and cytoplasmic staining of 4E-BP1 correlated with higher histological grade and poor outcome in a clinical study of human ovarian epithelial tumors (Castellvi et al. 2006).

Taken together, we have provided evidence that $4 \mathrm{E}-\mathrm{BP} 1$ localizes partly to the nucleus and regulates eIF4E nuclear levels by retaining it under stress conditions. This would suggest that nuclear $4 \mathrm{E}-\mathrm{BP}$ is a critical modulator of eIF4E activity and release from the nucleus. 4E-BP may regulate the export of eIF4E bound to certain mRNAs and/or release of free eIF4E to the cytoplasm for translation. Furthermore, the biological relevance of this regulation is apparent in Ras-expressing cells whereby eIF4E fails to accumulate in the nucleus in a manner that is dependent on $4 \mathrm{E}-\mathrm{BP}$ (or coincident with a loss of $4 \mathrm{E}-\mathrm{BP}$ in the nucleus). In this manner, 4E-BP localization may prove to be an important hallmark of oncogenic transformation (Armengol et al. 2007), and our study provides the molecular framework behind this premise.

\section{MATERIALS AND METHODS}

\section{Plasmid constructs}

pcDNA3-3HA-4E-BP1, pcDNA3-3HA-4E-BP2, and pACTAG2$3 \mathrm{HA}-4 \mathrm{E}-\mathrm{BP} 1(\triangle 4 \mathrm{EBS})$ have been described previously (Rousseau et al. 1996; Gingras et al. 1999a). pcDNA3-3HA-4E-BP1 (4Ala) carrying alanine substitutions at four phosphorylation sites (Thr37, Thr46, Ser65, and Thr70) was produced using the method previously described to generate the Thr37Ala, Thr46Ala double mutant protein (Gingras et al. 1999a), which had been shown to constitutively bind eIF4E. 4E-BP1, 4E-BP2, and mutant cDNA were amplified by PCR and inserted into BamHI/SalI sites of the retroviral vector $\mathrm{pBABE}$. $4 \mathrm{E}-\mathrm{BP} 1-\mathrm{CFP}$ was generated by fusing the open reading frame of 4E-BP1 in-frame with CFP from pcDNA3CFP (a kind gift from Dr. R.Y. Tsien, La Jolla, CA), using a PCRbased strategy. The 4E-BP1-CFP fusion is under control of the CMV promoter in pcDNA3. Primers and templates for PCRs are 
listed in Table 1. The 6.6-kb fragment from pEJ6.6 (Newbold and Overell 1983) encoding the $\mathrm{c}$-Ha-ras gene was cleaved with BamHI, blunted, and inserted into pcDNA3.1-Hygro to generate a Ras-expression construct.

\section{Antibodies}

Anti-4E-BP1 rabbit monoclonal antibody (clone 53H11) and anti4E-BP2 rabbit polyclonal antibody were from Cell Signaling Technology; anti-eIF4E mouse monoclonal antibody was from BD Transduction Labs; anti-eIF4E rabbit polyclonal antibody 5853 was described previously (Frederickson et al. 1992; Lejbkowicz et al. 1992); another anti-eIF4E monoclonal antibody was a gift from Dr. S. Kimball (Kimball et al. 2003; Ferraiuolo et al. 2005); anti-HA and anti-actin mouse monoclonal antibodies were from Sigma-Aldrich; and AlexaFluor 488 (or 594) conjugated secondary antibody was from Molecular Probes.

\section{Cell lines and cell culture}

Primary wild-type, $4 \mathrm{E}-\mathrm{BP} 1^{-/-}, 4 \mathrm{E}-\mathrm{BP} 2^{-/-}$, and $\mathrm{DKO}\left(4 \mathrm{E}-\mathrm{BP} 1^{-/-}\right.$/ $4 \mathrm{E}-\mathrm{BP} 2^{-1-}$ ) MEFs were previously described (Le Bacquer et al. 2007). Immortalized cell lines were established by passing cells for more than 16 generations, and experiments were performed using cells between passage 20 and 30. Cells were cultured in DMEM supplemented with $10 \%$ FBS and $1 \%$ penicillin/streptomycin, except during serum starvation, when DMEM containing $1 \%$ penicillin/streptomycin was applied. All plasmid and siRNA transfections were performed according to the manufacturer's instructions, using Lipofectamine Plus Reagent or Lipofectamine2000 (Invitrogen). To generate cell lines that stably express various 4E-BP mutants, pBABE constructs were transiently transfected into the Ecotropic Phoenix-293T packaging cell line. After 48 h, virus-containing medium was filtered $(0.45 \mu \mathrm{m})$, collected, and used to infect MEFs in the presence of $5 \mu \mathrm{g} / \mathrm{mL}$ polybrene (Sigma-
Aldrich). Infection was repeated the next day. Twenty-four hours after the second infection, medium supplemented with puromycin (1 $\mu \mathrm{g} / \mathrm{mL}$, Sigma-Aldrich) was added, and cells were subjected to selection for $1 \mathrm{wk}$ after which time colonies were pooled. pcDNA3.1-Hygro-c-Ha-Ras was transfected into MEFs. After $48 \mathrm{~h}$, medium supplemented with Hygromycin B $(250 \mu \mathrm{g} / \mathrm{mL}$, Bioshop) was applied for selection (1 wk).

\section{Immunofluorescence, flow cytometry, photobleaching, and immunohistochemistry}

Cells for immunofluorescence were seeded in Lab-Tek chamber slides (Nunc) at $60 \%$ confluency $24 \mathrm{~h}$ before treatment. After serum starvation and/or rapamycin (LC Labs) treatment, cells were fixed in $4 \%$ formaldehyde/PBS, permeabilized in $4 \%$ formaldehyde/PBS $/ 0.1 \%$ Triton X-100, and blocked with $50 \%$ FBS, $6 \%$ skim milk, $3 \%$ BSA, $0.1 \%$ Triton $\mathrm{X}-100$, and $0.05 \% \mathrm{NaN}_{3}$ in PBS (Lejbkowicz et al. 1992; Dostie et al. 2000a). Fixed cells were incubated with anti-4E-BP1 rabbit monoclonal antibody clone 53H11 (1:200), anti-eIF4E mouse monoclonal antibody (1:200), or anti-HA mouse monoclonal antibody (1:250) for $2 \mathrm{~h}$ at room temperature or overnight at $4^{\circ} \mathrm{C}$. After washing with $\mathrm{PBS}$, cells were incubated with AlexaFluor 488 (or 594) conjugated secondary antibodies (1:1000) (Molecular Probes) for $30 \mathrm{~min}$. Nuclei were stained with Hoechst 33258 (Sigma-Aldrich). Cells were washed extensively eight times with PBS/0.1\% Triton X100 for $10 \mathrm{~min}$ each time. Images were obtained using a $63 \times$ objective of a Zeiss LSM 510 confocal microscope. For c-Ha-Rasoverexpressing MEFs, continuously growing cells were either seeded in chamber slides at $60 \%$ confluency $24 \mathrm{~h}$ before treatment or mixed with parental cells at a ratio of $1: 9$, then seeded in culture for about $3 \mathrm{~d}$ until foci appeared. In the latter case, immunofluorescence was performed according to the same protocol described above.

TABLE 1. The primers and templates used to generate 4E-BP constructs

\begin{tabular}{|c|c|c|}
\hline Construct & Primer & Template \\
\hline pcDNA3-4E-BP1-CFP & $\begin{array}{l}\text { HindIII-4E-BP1-fwd: } \\
\text { CCCAAGCTTATGTCCGGGGGCAGCAGC } \\
\text { HindIII-4E-BP1-rev: } \\
\text { CCCAAGCTTGGTGGCGACCGGTGGATC }\end{array}$ & pcDNA3-3HA-4E-BP1 \\
\hline pBABE-HA-4E-BP1 & $\begin{array}{l}\text { HA-Bam-fwd: } \\
\text { GCTAGGATCCATGATCTATCCATATGAC } \\
\text { BP1-Sal-rev: } \\
\text { CGATGTCGACTTAAATGTCCATCTC }\end{array}$ & pcDNA3-3HA-4E-BP1 \\
\hline pBABE-HA-4E-BP2 & $\begin{array}{l}\text { HA-Bam-fwd: } \\
\text { GCTAGGATCCATGATCTATCCATATGAC } \\
\text { BP2-Sal-rev: } \\
\text { CGATGTCGACTCAGATGTCCATCTC }\end{array}$ & pcDNA3-3HA-4E-BP2 \\
\hline pBABE-HA-4E-BP1(4Ala) & $\begin{array}{l}\text { HA-Bam-fwd: } \\
\text { GCTAGGATCCATGATCTATCCATATGAC } \\
\text { BP1-Sal-rev: } \\
\text { CGATGTCGACTTAAATGTCCATCTC }\end{array}$ & pcDNA3-3HA-4E-BP1(4Ala) \\
\hline pBABE-HA-4E-BP1 $(\Delta 4 \mathrm{EBS})$ & $\begin{array}{l}\text { HA-Bam-fwd: } \\
\text { GCTAGGATCCATGATCTATCCATATGAC } \\
\text { BP1-Sal-rev: } \\
\text { CGATGTCGACTTAAATGTCCATCTC }\end{array}$ & pACTAG2-3HA-4E-BP1-( $\Delta 4 \mathrm{EBS})$ \\
\hline
\end{tabular}


To determine the relative fluorescent intensities of wild-type and DKO MEFs following immunostaining, cells were subjected to flow cytometric analysis using the primary antibody $(53 \mathrm{H} 11)$ according to the manufacturer's recommended protocol (Cell Signaling Technology). Briefly, cells were typsinized, fixed with $4 \%$ formaldehyde for $10 \mathrm{~min}$ at $37^{\circ} \mathrm{C}$, and then permeabilized with methanol for $30 \mathrm{~min}$ at $-20^{\circ} \mathrm{C}$. After $1 \mathrm{~h}$ blocking with $2 \%$ BSA (in PBS), cells were incubated with the 4E-BP1 antibody (clone $53 \mathrm{H} 11,1: 200$ ) overnight at $4^{\circ} \mathrm{C}$, and AlexaFluor 488 conjugated goat anti-rabbit IgG (1:1000) for $1 \mathrm{~h}$. After washing with PBS, cells were analyzed using a Beckton Dickinson FACScan.

The pcDNA3-4E-BP1-CFP mammalian expression construct was transiently transfected into wild-type MEFs plated in $3.5-\mathrm{cm}$ Petri dishes with a 25-mm circular microscope cover glass (Fisher). A photobleaching assay was performed $24 \mathrm{~h}$ later in a $37^{\circ} \mathrm{C}$ chamber with a supply of $5 \% \mathrm{CO}_{2}$, using a Zeiss LSM510 Meta microscope. A 25-mW diode laser generating a 405-nm line was used in combination with a band pass filter reading of 470 $500 \mathrm{~nm}$. Images were acquired at $0.5-\mathrm{mW}$ power prior to photobleaching. The nucleus was bleached for $5 \mathrm{sec}$ using the $405-\mathrm{nm}$ laser line at $100 \%$ intensity. Single images were then collected for $300-600 \mathrm{sec}$ at the indicated time points using $0.5-\mathrm{mW}$ power. Using the Metamorph software, fluorescence intensities of all the pixels representing the nuclear and cytoplasmic area were measured, and the average intensity of the photobleached nucleus was normalized against the average intensity of the cytoplasm. This experiment was repeated for seven different cells.

Immunohistochemistry was performed according to the primary antibody manufacturer's protocol (Cell Signaling Technology). Briefly, mouse tissues were fixed overnight at room temperature in $10 \%$ neutral buffered formalin. Four-millimeter sections were deparaffinized in xylene for $5 \mathrm{~min}$ three times, and rehydrated through two washes of $100 \%$ ethanol for 10 min each and two washes of $95 \%$ ethanol for $10 \mathrm{~min}$ each. Antigen unmasking was performed using $10 \mathrm{mM}$ sodium citrate $(\mathrm{pH}$ 6.0) at a sub-boiling temperature for $10 \mathrm{~min}$. After quenching in $3 \% \mathrm{H}_{2} \mathrm{O}_{2}$ for $10 \mathrm{~min}$, slides were blocked with $5 \%$ horse serum in PBS supplemented with $0.1 \%$ Tween-20 for $1 \mathrm{~h}$ at room temperature. Tissues were stained with primary antibody overnight at $4^{\circ} \mathrm{C}$ and secondary antibody for $30 \mathrm{~min}$ at room temperature. Detection was performed with Vector ABC Elite kit and NovaRed substrate (Vector Labs). Slides were dehydrated by incubating with $95 \%$ ethanol, $100 \%$ ethanol, and xylene for $10 \mathrm{sec}$ each and mounted with coverslips.

\section{ACKNOWLEDGMENTS}

We thank J. Laliberte and C. Brown for excellent technical support with confocal microscopy; M. M'Boutchou for generation of immortalized MEF cell lines; Jianxin Xie for advanced access to the 4E-BP1 (53H11) rabbit monoclonal antibody; and C. Lister and P. Kirk for assistance. This research was supported by grants from the National Cancer Institute of Canada (NCIC) and Canadian Institute of Health Research (CIHR). L.R. was a recipient of a postdoctoral fellowship from the CIHR and a CIHR Cancer Consortium Training Grant Fellowship from McGill Cancer Center. M.L. and R.S. were supported by McGill-CIHR Chemical Biology Fellowships. E.P. was supported by a fellowship from the Cancer Research Society and a Chemical Biology Fellowship from McGill University. N.S. is a CIHR distinguished scientist and a Howard Hughes Medical Institute International Scholar.

Received December 10, 2007; accepted April 15, 2008.

\section{REFERENCES}

Armengol, G., Rojo, F., Castellvi, J., Iglesias, C., Cuatrecasas, M., Pons, B., Baselga, J., and Ramon y Cajal, S. 2007. 4E-binding protein 1: A key molecular "funnel factor" in human cancer with clinical implications. Cancer Res. 67: 7551-7555.

Beretta, L., Gingras, A.C., Svitkin, Y.V., Hall, M.N., and Sonenberg, N. 1996. Rapamycin blocks the phosphorylation of 4E-BP1 and inhibits cap-dependent initiation of translation. EMBO J. 15: 658-664.

Castellvi, J., Garcia, A., Rojo, F., Ruiz-Marcellan, C., Gil, A., Baselga, J., and Ramon y Cajal, S. 2006. Phosphorylated 4E binding protein 1: A hallmark of cell signaling that correlates with survival in ovarian cancer. Cancer 107: 1801-1811.

Cuesta, R., Laroia, G., and Schneider, R.J. 2000. Chaperone hsp27 inhibits translation during heat shock by binding eIF4G and facilitating dissociation of cap-initiation complexes. Genes \& Dev. 14: 1460-1470.

Dostie, J., Ferraiuolo, M., Pause, A., Adam, S.A., and Sonenberg, N. 2000a. A novel shuttling protein, 4E-T, mediates the nuclear import of the mRNA $5^{\prime}$-cap-binding protein, eIF4E. EMBO J. 19: $3142-3156$.

Dostie, J., Lejbkowicz, F., and Sonenberg, N. 2000b. Nuclear eukaryotic initiation factor $4 \mathrm{E}$ (eIF4E) colocalizes with splicing factors in speckles. J. Cell Biol. 148: 239-247.

Ferraiuolo, M.A., Basak, S., Dostie, J., Murray, E.L., Schoenberg, D.R., and Sonenberg, N. 2005. A role for the eIF4E-binding protein 4E-T in P-body formation and mRNA decay. J. Cell Biol. 170: 913924.

Fingar, D.C. and Blenis, J. 2004. Target of rapamycin (TOR): An integrator of nutrient and growth factor signals and coordinator of cell growth and cell cycle progression. Oncogene 23: 3151-3171.

Frederickson, R.M., Mushynski, W.E., and Sonenberg, N. 1992. Phosphorylation of translation initiation factor eIF-4E is induced in a ras-dependent manner during nerve growth factor-mediated PC12 cell differentiation. Mol. Cell. Biol. 12: 1239-1247.

Gingras, A.C., Kennedy, S.G., O'Leary, M.A., Sonenberg, N., and Hay, N. 1998. 4E-BP1, a repressor of mRNA translation, is phosphorylated and inactivated by the Akt $(\mathrm{PKB})$ signaling pathway. Genes \& Dev. 12: 502-513.

Gingras, A.C., Gygi, S.P., Raught, B., Polakiewicz, R.D., Abraham, R.T., Hoekstra, M.F., Aebersold, R., and Sonenberg, N. 1999a. Regulation of 4E-BP1 phosphorylation: A novel two-step mechanism. Genes \& Dev. 13: 1422-1437.

Gingras, A.C., Raught, B., and Sonenberg, N. 1999b. eIF4 initiation factors: effectors of mRNA recruitment to ribosomes and regulators of translation. Annu. Rev. Biochem. 68: 913-963.

Gingras, A.C., Raught, B., Gygi, S.P., Niedzwiecka, A., Miron, M., Burley, S.K., Polakiewicz, R.D., Wyslouch-Cieszynska, A., Aebersold, R., and Sonenberg, N. 2001. Hierarchical phosphorylation of the translation inhibitor 4E-BP1. Genes \& Dev. 15: 2852-2864.

Gorlich, D. and Kutay, U. 1999. Transport between the cell nucleus and the cytoplasm. Annu. Rev. Cell Dev. Biol. 15: 607-660.

Graff, J.R., Konicek, B.W., Vincent, T.M., Lynch, R.L., Monteith, D., Weir, S.N., Schwier, P., Capen, A., Goode, R.L., Dowless, M.S., et al. 2007. Therapeutic suppression of translation initiation factor eIF4E expression reduces tumor growth without toxicity. J. Clin. Invest. 117: 2638-2648.

Haghighat, A., Mader, S., Pause, A., and Sonenberg, N. 1995. Repression of cap-dependent translation by $4 \mathrm{E}$-binding protein 1: Competition with p220 for binding to eukaryotic initiation factor-4E. EMBO J. 14: 5701-5709. 
Hershey, J.W.B. and Merrick, W.C. 2000. Pathway and mechanism of initiation of protein synthesis. In Translational control, 2nd ed. (eds. M.B. Mathews and N. Sonenberg), pp. 33-88. Cold Spring Harbor Laboratory, Cold Spring Harbor, NY.

Hicks, G.R. and Raikhel, N.V. 1995. Protein import into the nucleus: An integrated view. Annu. Rev. Cell Dev. Biol. 11: 155-188.

Inoki, K., Li, Y., Zhu, T., Wu, J., and Guan, K.L. 2002. TSC2 is phosphorylated and inhibited by Akt and suppresses mTOR signalling. Nat. Cell Biol. 4: 648-657.

Kim, J.E. and Chen, J. 2000. Cytoplasmic-nuclear shuttling of FKBP12-rapamycin-associated protein is involved in rapamycinsensitive signaling and translation initiation. Proc. Natl. Acad. Sci. 97: 14340-14345.

Kimball, S.R., Horetsky, R.L., Ron, D., Jefferson, L.S., and Harding, H.P. 2003. Mammalian stress granules represent sites of accumulation of stalled translation initiation complexes. Am. J. Physiol. Cell Physiol. 284: C273-C284.

Kleijn, M., Scheper, G.C., Wilson, M.L., Tee, A.R., and Proud, C.G. 2002. Localisation and regulation of the eIF4E-binding protein $4 \mathrm{E}-$ BP3. FEBS Lett. 532: 319-323.

Knippschild, U., Oren, M., and Deppert, W. 1996. Abrogation of wild-type p53 mediated growth-inhibition by nuclear exclusion. Oncogene 12: 1755-1765.

Lang, V., Zanchin, N.I., Lunsdorf, H., Tuite, M., and McCarthy, J.E. 1994. Initiation factor eIF-4E of Saccharomyces cerevisiae. Distribution within the cell, binding to mRNA, and consequences of its overproduction. J. Biol. Chem. 269: 6117-6123.

Le Bacquer, O., Petroulakis, E., Paglialunga, S., Poulin, F., Richard, D., Cianflone, K., and Sonenberg, N. 2007. Elevated sensitivity to dietinduced obesity and insulin resistance in mice lacking 4E-BP1 and 4E-BP2. J. Clin. Invest. 117: 387-396.

Lejbkowicz, F., Goyer, C., Darveau, A., Neron, S., Lemieux, R., and Sonenberg, N. 1992. A fraction of the mRNA $5^{\prime}$-cap-binding protein, eukaryotic initiation factor $4 \mathrm{E}$, localizes to the nucleus. Proc. Natl. Acad. Sci. 89: 9612-9616.

Lin, T.A., Kong, X., Saltiel, A.R., Blackshear, P.J., and Lawrence Jr., J.C. 1995. Control of PHAS-I by insulin in 3T3-L1 adipocytes. Synthesis, degradation, and phosphorylation by a rapamycinsensitive and mitogen-activated protein kinase-independent pathway. J. Biol. Chem. 270: 18531-18538.

Ma, L., Chen, Z., Erdjument-Bromage, H., Tempst, P., and Pandolfi, P.P. 2005. Phosphorylation and functional inactivation of TSC2 by Erk implications for tuberous sclerosis and cancer pathogenesis. Cell 121: 179-193.

Mamane, Y., Petroulakis, E., Rong, L., Yoshida, K., Ler, L.W., and Sonenberg, N. 2004. eIF4E-from translation to transformation. Oncogene 23: 3172-3179.

Marte, B.M. and Downward, J. 1997. PKB/Akt: Connecting phosphoinositide 3-kinase to cell survival and beyond. Trends Biochem. Sci. 22: 355-358.

Mothe-Satney, I., Yang, D., Fadden, P., Haystead, T.A., and Lawrence Jr., J.C. 2000. Multiple mechanisms control phosphorylation of
PHAS-I in five (S/T)P sites that govern translational repression. Mol. Cell. Biol. 20: 3558-3567.

Newbold, R.F. and Overell, R.W. 1983. Fibroblast immortality is a prerequisite for transformation by EJ c-Ha-ras oncogene. Nature 304: 648-651.

Pause, A., Belsham, G.J., Gingras, A.C., Donze, O., Lin, T.A., Lawrence Jr., J.C., and Sonenberg, N. 1994. Insulin-dependent stimulation of protein synthesis by phosphorylation of a regulator of $5^{\prime}$-cap function. Nature 371: 762.

Pestova, T.V., Lorsch, J.R., and Hellen, C.U. 2007. The mechanism of translation initiation in eukaryotes. In Translational control in biology and medicine. (M.B. Mathews and J.W.B. Hershey), pp. 87-128. Cold Spring Harbor Laboratory, Cold Spring Harbor, NY.

Poulin, F., Gingras, A.C., Olsen, H., Chevalier, S., and Sonenberg, N. 1998. 4E-BP3, a new member of the eukaryotic initiation factor 4E-binding protein family. J. Biol. Chem. 273: 14002-14007.

Reiling, J.H. and Sabatini, D.M. 2006. Stress and mTORture signaling. Oncogene 25: 6373-6383.

Rousseau, D., Kaspar, R., Rosenwald, I., Gehrke, L., and Sonenberg, N. 1996. Translation initiation of ornithine decarboxylase and nucleocytoplasmic transport of cyclin D1 mRNA are increased in cells overexpressing eukaryotic initiation factor 4E. Proc. Natl. Acad. Sci. 93: 1065-1070.

Rozen, F., Edery, I., Meerovitch, K., Dever, T.E., Merrick, W.C., and Sonenberg, N. 1990. Bidirectional RNA helicase activity of eucaryotic translation initiation factors 4A and 4F. Mol. Cell. Biol. 10: 1134-1144.

Tokunaga, C., Yoshino, K., and Yonezawa, K. 2004. mTOR integrates amino acid- and energy-sensing pathways. Biochem. Biophys. Res. Commun. 313: 443-446.

Topisirovic, I., Culjkovic, B., Cohen, N., Perez, J.M., Skrabanek, L., and Borden, K.L. 2003. The proline-rich homeodomain protein, $\mathrm{PRH}$, is a tissue-specific inhibitor of eIF4E-dependent cyclin D1 mRNA transport and growth. EMBO J. 22: 689-703.

Tsukiyama-Kohara, K., Poulin, F., Kohara, M., DeMaria, C.T., Cheng, A., Wu, Z., Gingras, A.C., Katsume, A., Elchebly, M., Spiegelman, B.M., et al. 2001. Adipose tissue reduction in mice lacking the translational inhibitor 4E-BP1. Nat. Med. 7: 1128-1132.

Wang, X., Li, W., Parra, J.L., Beugnet, A., and Proud, C.G. 2003. The $\mathrm{C}$ terminus of initiation factor $4 \mathrm{E}$-binding protein 1 contains multiple regulatory features that influence its function and phosphorylation. Mol. Cell. Biol. 23: 1546-1557.

Wei, X., Henke, V.G., Strubing, C., Brown, E.B., and Clapham, D.E. 2003. Real-time imaging of nuclear permeation by EGFP in single intact cells. Biophys. J. 84: 1317-1327.

Wullschleger, S., Loewith, R., and Hall, M.N. 2006. TOR signaling in growth and metabolism. Cell 124: 471-484.

Zhang, X., Shu, L., Hosoi, H., Murti, K.G., and Houghton, P.J. 2002. Predominant nuclear localization of mammalian target of rapamycin in normal and malignant cells in culture. J. Biol. Chem. 277: 28127-28134. 

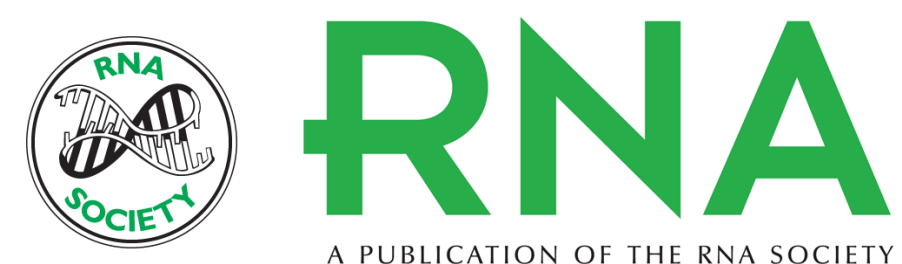

A PUBLICATION OF THE RNA SOCIETY

\section{Control of elF4E cellular localization by elF4E-binding proteins, 4E-BPs}

Liwei Rong, Mark Livingstone, Rami Sukarieh, et al.

RNA 2008 14: 1318-1327

References This article cites 43 articles, 19 of which can be accessed free at: http://rnajournal.cshlp.org/content/14/7/1318.full.html\#ref-list-1

\section{License}

Email Alerting Receive free email alerts when new articles cite this article - sign up in the box at the Service top right corner of the article or click here.

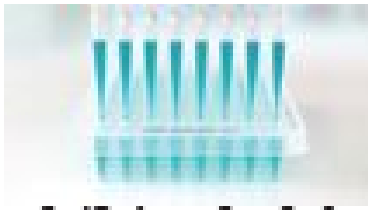

